\title{
Trends in prenatal diagnosis of congenital anomalies among live births over a 30-year period
}

Karina Dyrvig Honore* and Ester Garne

*Correspondence: karinadyrvig@gmail.com

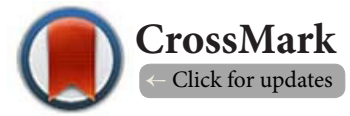

Department of Paediatrics, Hospital Lillebaelt, Kolding, Denmark.

\begin{abstract}
Background: In 2004 the Danish National Board of Health changed its screening recommendations. A first trimester screening for Down's syndrome and a prenatal ultrasound screening for congenital anomalies in the second trimester was now offered to all pregnant women. The aim of this study was to describe the development in prenatal diagnosis of congenital anomalies in live born infants over the past 30 years.
\end{abstract}

Methods: The study was based on data from the EUROCAT Registry for Funen County and included all live births with a prenatal diagnosis of a congenital anomaly. Data were compared over four periods of time (1980-89, 1990-99, 2000-04, and 2005-09).

Results: The types of congenital anomalies among live births with a prenatal diagnosis changed significantly. Infants with less severe anomalies accounted for $69 \%$ of the total number of live births with prenatal diagnoses in 2005-09 while the same group in 1990-99 only accounted for 35\% ( $<<0.001)$. Two fetuses were diagnosed prenatally with clubfoot in 2000-04 and one with cleft lip, while the numbers in 2005-09 was 12 and 14 respectively. Number of infants born in 2005-09 with a prenatal diagnosis of hydronephrosis tripled since the $90 \mathrm{~s}$.

Conclusion: After the change in the prenatal screening programme in Denmark, an increasing number of pregnant women go through the second half of pregnancy knowing that their fetus has a less severe congenital anomaly, which may require treatment postnatally. Knowledge of the psychological impact, both positive and negative, for the parents is very limited.

Keywords: Prenatal ultrasound screening, prenatal diagnosis, congenital anomalies, psychological impact

\section{Introduction}

Prenatal screening for congenital anomalies is performed in most European countries [1]. In Denmark, prenatal screening using invasive testing for Down syndrome has been offered for advanced maternal age for more than 30 years. Until 2005 prenatal ultrasound examinations were performed for specific indications only.

In 2004 the Danish National Board of Health changed its screening recommendations. As of 2005 a first trimester screening for Down syndrome and a prenatal ultrasound screening for congenital anomalies in the second trimester of pregnancy was offered to all pregnant women [2].

In the first trimester a combined test is offered by gestational age (GA) $11+0-13+6$ weeks. The combined test consists of maternal pregnancy-associated plasma protein $A$ and human chorionic gonadotropin (b-hCG) plasma values and nuchal translucency. This gives a risk assessment for serious chromosome anomalies, such as trisomy 21 , trisomy 13 , and trisomy 18 , and detects lethal congenital anomalies, such as anencephaly [3].

In the second trimester (GA 18+0-21+0 weeks) a congenital anomaly scan is offered with the purpose to diagnose severe structural congenital anomalies, such as spina bifida, hydrocephalus, and severe renal anomalies. During the anomalyscan, the organs of the fetus are systematically examined and the bones in upper and lower limbs are counted. The ultrasonographer is instructed not to look for "soft markers," which are defined as non-specific anatomic variations.

Over the decades the quality of ultrasonography has improved considerably [4] and it is now also possible to perform 3D and 4D scans. Thus, some less severe congenital anomalies, such as cleft lip and club foot, can be diagnosed by ultrasonography in the second trimester [5]. The advice and information given 
Honore et al. Journal of Reproductive Biology and Health 2014,

http://www.hoajonline.com/journals/pdf/2054-0841-2-1.pdf

to expectant parents after prenatal diagnosis of a congenital anomaly are therefore very different today than 20-30 years ago.

The current study describes the development in prenatal diagnosis among live births for Funen County, Denmark covering a 30-year period (1980-2009).

\section{Material and methods}

The study was based on routinely collected data from the EUROCAT registry of Funen County [6]. EUROCAT is a European network of population-based registers with the main aim to monitor the prevalence of congenital anomalies over time and to detect unnatural changes. The registries are based on multiple sources of information, including hospital records, birth and death certificates, annual reports from the cytogenetic laboratory, and post-mortem examinations. The inclusion criteria were major congenital anomalies among live births (LB), fetal deaths (FD) with a gestational age (GA) of $>20$ weeks, and termination of pregnancy (TOPFA) at any GA after the prenatal diagnosis of a fetal anomaly.

All structural malformations, syndromes, and chromosomal anomalies were included in the database, except minor and poorly specified anomalies found on an exclusion list. Hydronephrosis was included if the pelvic diameter was $>$ $10 \mathrm{~mm}$ postnatally.

Our study population included all fetuses/infants born between 1980 and 2009. Prenatal diagnosis data of LB were compared over four periods of time (1980-1989, 1990-1999, 2000-2004, and 2005-2009). The data set included the following variables: year of birth, birth type (LB, FD, and TOPFA), GA at prenatal diagnosis, all congenital anomaly diagnoses and survival within the first week of life. LB with non-chromosomal congenital anomalies were classified according to severity. Lethal congenital anomalies were defined as anomalies that are not compatible with life despite optimal treatment, such as anencephaly and bilateral renal agenesis. Severe congenital anomalies were defined as anomalies with a high mortality without treatment, such as spina bifida and severe congenital heart defects. Less severe congenital anomalies were defined as anomalies with low mortality, such as unilateral renal malformations, cleft lip and palate, and club foot.

A chi-square test was used to calculate $p$ values when appropriate.

\section{Results}

The registry data included 4043 cases with congenital anomalies born between 1980 and 2009. Of all cases, 87\% were live born, ranging from $92 \%$ in $1980-1989$ to $80.0 \%$ in 2005-2009 (Table 1).

Among the 3490 LB with congenital anomalies, 322 (9.2\%) were diagnosed prenatally. The prenatal detection rate increased over time (from $3.2 \%$ in $1980-1989$ to $18.4 \%$ in 2005-2009; $p<0.001)$. The mortality in the first week of life among LB with a prenatal diagnosis decreased significantly from at least $35 \%$ in the 1980 s to $4.8 \%$ in $2005-2009$ ( $p<0.001)$.
Survival in the first week of life was only known by the Registry for 10 of the 23 infants born in 1980-1989. Over the 30 years, the number of TOPFA increased, while the number of fetal deaths from GA 20 weeks slightly decreased (Table 1).

The types of congenital anomalies among LB with prenatal diagnoses have changed significantly over the decades. Thus, the number of children born in 2005-2009 with a prenatal diagnosis of hydronephrosis tripled since the 1990s. One and two fetuses with cleft lip and palate and club foot were diagnosed prenatally in the 2000-2004 period, while the number after 2005 was 14 and 12, respectively (Figure 1).

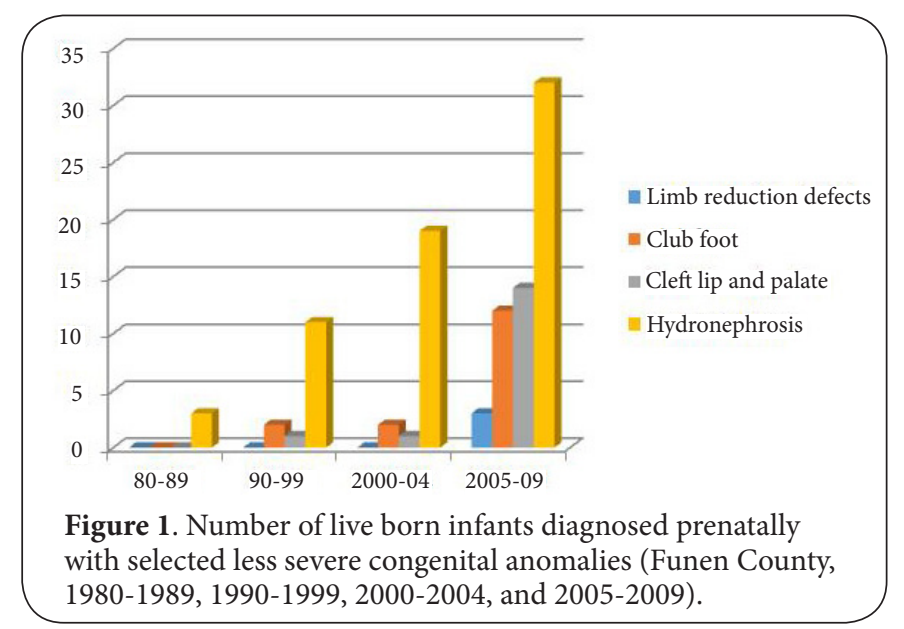

Table 2 shows non-chromosomal congenital anomalies in LB with prenatal diagnoses classified by severity. The number of lethal and severe congenital anomalies decreased, while the number of less severe anomalies increased significantly. The group with less severe congenital anomalies accounted for $69 \%(81 / 117)$ of the total number of LB with prenatal diagnoses in the 2005-2009 period, while the same group in the 1990s only accounted for $35 \%(28 / 79)(p<0.001)$. GA at discovery also changed over time as less than one-third of LB diagnosed prenatally were detected earlier than GA 21 weeks in the 1990s, this increased to more than 50\% after 2005. Further, the median GA of diagnosis decreased by 10 weeks from the 1990s to 2005-2009.

\section{Discussion}

We have described the development in prenatal diagnosis for live born infants with congenital anomalies between 1980 and 2009. There have been major changes in prenatal diagnostics during these 30 years. In the 1980s and 1990s, there were few terminations of pregnancy for fetal anomalies and the live born infants with a prenatal diagnosis often had a lethal or severe congenital anomaly diagnosed late in pregnancy. In the last decade the number of TOPFA with severe congenital anomalies has increased, and at the same time, more live born infants have been diagnosed prenatally with less severe congenital anomaly. 
Table 1. Cases with congenital anomalies by pregnancy outcome, prenatal diagnosis in live births, and mortality in the first week of life of those with a prenatal diagnosis (Funen County, 1980-2009).

\begin{tabular}{|c|c|c|c|c|c|c|c|}
\hline & $\begin{array}{l}\text { Total births } \\
\text { Funen } \\
\text { County }\end{array}$ & $\begin{array}{l}\text { Cases with } \\
\text { congenital } \\
\text { anomalies }\end{array}$ & $\begin{array}{l}\text { Fetal deaths with } \\
\text { congenital } \\
\text { anomalies } \\
(\mathrm{GA} \geq 20 \text { weeks })\end{array}$ & $\begin{array}{l}\text { Terminations of } \\
\text { pregnancy after the } \\
\text { prenatal diagnosis } \\
\text { of a fetal anomaly }\end{array}$ & $\begin{array}{l}\text { Live births } \\
\text { with congenital } \\
\text { anomalies }\end{array}$ & $\begin{array}{l}\text { Live births with a } \\
\text { prenatal diagnosis of } \\
\text { congenital anomaly } \\
\text { (\% of live births) }\end{array}$ & $\begin{array}{l}\text { Deaths in the first } \\
\text { week of life \% of live } \\
\text { births diagnosed } \\
\text { prenatally }\end{array}$ \\
\hline 1980-1989 & 47.850 & 1.099 & $47(4.3 \%)$ & $43(3.9 \%)$ & $1.009(92 \%)$ & $23(2.3 \%)$ & Minimum 35\% \\
\hline 1990-1999 & 58.253 & 1.361 & $57(4.2 \%)$ & $122(9.0 \%)$ & $1.182(87.3 \%)$ & $90(7.6 \%)$ & $25 \%$ \\
\hline 2000-2004 & 26.745 & 727 & $17(2.4 \%)$ & $88(12.3 \%)$ & $622(86.8 \%)$ & $85(13.7 \%)$ & $16.5 \%$ \\
\hline 2005-2009 & 26.746 & 856 & $17(2.0 \%)$ & $157(18.4 \%)$ & $682(80.0 \%)$ & $124(18.2 \%)$ & $4.8 \%$ \\
\hline Total n (\%) & 159.594 & 4.046 & $138(3.4 \%)$ & $410(10.2 \%)$ & $3.495(86.3 \%)$ & $322(9.2 \%)$ & -- \\
\hline
\end{tabular}

Table 2. Live births (LB) with prenatal diagnosis of a non-chromosomal congenital anomaly by time period and severity and gestational age (GA) when diagnosed (Funen County, 1980-2009).

\begin{tabular}{|c|c|c|c|c|}
\hline & 1980-89 & 1990-99 & 2000-04 & 2005-09 \\
\hline Number of LB diagnosed prenatally with a lethal congenital anomaly & 3 & 7 & 2 & 1 \\
\hline Median GA at prenatal diagnosis (range) & -- & $25(18-42)$ & $25(19-31)$ & 29 \\
\hline Number of LB diagnosed prenatally with a severe congenital anomaly & 11 & 44 & 39 & 35 \\
\hline Median GA at prenatal diagnosis (range) & -- & $30(17-41)$ & $30(12-40)$ & $20(12-37)$ \\
\hline Number of LB diagnosed prenatally with a less severe congenital anomaly & 4 & 28 & 36 & 81 \\
\hline Median GA at prenatal diagnosis (range) & -- & $33(17-42)$ & $24(16-39)$ & $20(12-37)$ \\
\hline Total LB with a prenatal non-chromosomal diagnosis & 18 & 79 & 77 & 117 \\
\hline GA $<15$ weeks at prenatal diagnosis $n(\%)$ & -- & 0 & $1(1 \%)$ & $2(2 \%)$ \\
\hline GA 15-21 weeks at prenatal diagnosis n (\%) & 1 & $22(28 \%)$ & $25(32 \%)$ & $64(55 \%)$ \\
\hline GA 22-36 weeks at prenatal diagnosis n (\%) & 1 & $37(47 \%)$ & $41(53 \%)$ & $47(40 \%)$ \\
\hline $\mathrm{GA} \geq 37$ weeks at prenatal diagnosis $n(\%)$ & & $18(23 \%)$ & $10(13 \%)$ & $3(3 \%)$ \\
\hline Unknown GA at prenatal diagnosis & 16 & $2(3 \%)$ & 0 & $1(1 \%)$ \\
\hline Median GA at prenatal diagnosis & -- & 30 & 27 & 20 \\
\hline
\end{tabular}

However, not all congenital anomalies can be diagnosed prenatally. In the latest 5-year period of this study, approximately $20 \%$ of all congenital anomalies in live born infants were diagnosed prenatally. In addition, some pregnant women chose not to participate in the screening program or the pregnancy was recognized too late for first or the second trimester screening. Therefore, a prenatal detection rate will never reach $100 \%$.

Other studies have found prenatal detection rates higher than in our region. In a British study the prenatal detection rate of all congenital anomalies and all birth outcomes increased from $48 \%$ in $1991-1993$ to $61 \%$ in $2006-2008$ [7]. In the same study, the percentage of prenatally diagnosed cases detected before 14 weeks GA increased from $6 \%$ in 1991-1993 to $27 \%$ in 2006-2008. A recent study from Sweden [8] found a prenatal detection rate at $68 \%$ for chromosomally normal fetuses. Comparing prenatal detection rates between studies may seem meaningless due to different inclusion criteria. Our study included all congenital anomalies diagnosed up to the age of 5 years. Other studies only include congenital anomalies that can be diagnosed prenatally and/or only include postnatally diagnosed cases up to the age of one week or one month after birth. Further the variation in the detection rate may also reflect differences in examination skill and quality of equipment and also differences between studies in the definition of agreement between prenatal and postnatal diagnosis. Therefore it is mainly of interest to look at the difference in detection rates within the same study area over time [8].

We found a highly significant decrease in mortality in the first week of life for the group of infants with a prenatal diagnosis. This is explained by the difference in the severity of congenital anomalies prenatally diagnosed in live births over time, with mainly lethal and severe anomalies diagnosed late in pregnancy in the 1980s. The majority of lethal anomalies in the latest time period was diagnosed prenatally in the first or second trimester of pregnancy, followed by termination of pregnancy, and is therefore not included as a first week mortality. In another study from the same population, it was found that the neonatal mortality among all live born infants with congenital anomalies has decreased significantly after the introduction of the prenatal screening program [9]. A randomized case-control 
study on prenatal ultrasound screening in the second trimester of pregnancy showed a significant decrease in perinatal mortality in the ultrasound group, mainly explained by an increase in terminations of pregnancy for lethal and severe congenital anomalies [10].

In the 1980s the clinical situation with prenatal diagnosis in live born infants was often a diagnosis of a lethal or very severe anomaly acknowledged late in pregnancy. After 2005 the number of pregnancies with a second trimester prenatal diagnosis of severe and less severe congenital anomalies has increased significantly. These expectant parents will, for approximately one-half of the pregnancy, have the knowledge that their infant will be born with a congenital anomaly and may require treatment shortly after birth or at some point during early childhood. Some of these parents have, at the time of diagnosis, been presented for the possibility of choosing termination of pregnancy as the pregnancy outcome. There is very little information in the literature regarding the psychological effects (both positive and negative) of the prenatal diagnosis for these parents.

The prerequisite that the pregnant woman/couple can make the decision whether or not to terminate or continue the pregnancy after a prenatal diagnosis of a severe congenital anomaly depends on how well the pregnant woman is informed about the anomaly scan and its benefits and limitations. At the same time, information of treatment options and the prognosis after the diagnosis given to the couple is very important, because the decision on TOPFA has to be made quickly [11]. A US study showed that pregnant women are not sufficiently well informed about the purpose of the prenatal ultrasound scans. Many women participated in the prenatal screening program because they were looking forward to seeing their unborn baby and because they wanted to know the gender. Others decided to participate in the program because it was the norm in society and because their physician referred them for the scan. The majority of women who attended the screening program indicated that they never thought anything would be wrong with the fetus, and they did not talk to the father of the baby or the health providers about this risk and what to do if the ultrasound diagnosed a congenital anomaly [12]. In Denmark the National Board of Health has published guidelines on how to inform pregnant women before they give consent for the prenatal screening programme and are referred for the examinations.

In addition to the infants with hydronephrosis who are included in the Registry, some fetuses are diagnosed with hydronephrosis prenatally without postnatal confirmation of the diagnosis (pelvic diameter $<10 \mathrm{~mm}$ after birth). Only limited research has been conducted involving false-positive prenatal diagnoses, but it has been shown that such findings increase the level of anxiety and depression in women during the remainder of the pregnancy and affects the mother-infant interaction negatively for up to 2 months postpartum. A French study showed that fewer infants are breastfed by mothers whose fetuses are diagnosed prenatally with a congenital anomaly that is subsequently shown to be a false-positive finding. In the same study it was also reported that mothers expressed fewer positive emotions towards the infant and had difficulties perceiving and elaborating the signals from their infants. Also, the infants showed fewer positive emotions and initiative behavior towards the mother [13].

\section{Conclusion}

With the Danish prenatal screening program implemented in 2005, most lethal and severe congenital anomalies are diagnosed prenatally in the first and second trimesters of pregnancy with the option of terminating the pregnancy [9]. As a consequence of this screening program, an increasing number of pregnant women go through the second half of the pregnancy knowing that the fetus has a less severe congenital anomaly, which may require treatment postnatally. A few studies indicated that this knowledge affects the pregnancy negatively and in the first months postpartum the motherinfant interaction may be affected negatively. However, the evidence is sparse and knowledge of the psychological impact both positively and negatively for these parents is limited. Indeed, it is not known how pregnant women in Denmark cope with this knowledge. More research on the psychological effects is needed to give the professionals knowledge on how to provide the best care and support to the pregnant woman/couple in the remainder of the pregnancy and in the first months after birth.

\section{Competing interests}

The authors declare that they have no competing interests.

Authors' contributions

\begin{tabular}{|l|c|c|}
\hline Authors' contributions & KDH & EG \\
\hline Research concept and design & $\checkmark$ & $\checkmark$ \\
\hline Collection and/or assembly of data & $\checkmark$ & $\checkmark$ \\
\hline Data analysis and interpretation & $\checkmark$ & $\checkmark$ \\
\hline Writing the article & $\checkmark$ & -- \\
\hline Critical revision of the article & -- & $\checkmark$ \\
\hline Final approval of article & $\checkmark$ & $\checkmark$ \\
\hline Statistical analysis & $\checkmark$ & $\checkmark$ \\
\hline
\end{tabular}

Publication history

Editors: Giampiero Capobianco, University of Sassari, Italy. Eliezer Shalev, Technion-Israel Institute of Technology, Israel. Kowalcek Ingrid, Medical University of Schleswig Holstein, Germany.

Received: 26-May-2014 Final Revised: 09-Jul-2014

Accepted: 07-Aug-2014 Published: 01-Sep-2014

\section{References}

1. Boyd PA, Devigan C, Khoshnood B, Loane M, Garne E and Dolk H. Survey of prenatal screening policies in Europe for structural malformations and chromosome anomalies, and their impact on detection and termination rates for neural tube defects and Down's syndrome. BJOG. 
Honore et al. Journal of Reproductive Biology and Health 2014, http://www.hoajonline.com/journals/pdf/2054-0841-2-1.pdf

2008; 115:689-96. | Article | PubMed Abstract | PubMed Full Text

2. Sundhedsstyrelsen. Retningslinjer for fosterdiagnostik. | Pdf

3. Froslev-Friis C, Hjort-Pedersen K, Henriques CU, Krogh LN and Garne E. Improved prenatal detection of chromosomal anomalies. Dan Med Bull. 2011; 58:A4293. | Article | PubMed

4. Richmond $S$ and Atkins J. A population-based study of the prenatal diagnosis of congenital malformation over 16 years. BJOG. 2005; 112:1349-57. | Article | PubMed

5. Ensing $\mathrm{S}$, Kleinrouweler $\mathrm{CE}$, Maas $\mathrm{SM}$, Bilardo $\mathrm{CM}$, Van der Horst $\mathrm{CM}$ and Pajkrt E. Influence of the 20-week anomaly scan on prenatal diagnosis and management of fetal facial clefts. Ultrasound Obstet Gynecol. 2014; 44:154-9. | Article | PubMed

6. Boyd PA, Haeusler M, Barisic I, Loane M, Garne E and Dolk H. Paper 1: The EUROCAT network--organization and processes. Birth Defects Res A Clin Mol Teratol. 2011; 91 Suppl 1:S2-15. I Article I PubMed

7. Boyd PA, Rounding C, Chamberlain P, Wellesley D and Kurinczuk JJ. The evolution of prenatal screening and diagnosis and its impact on an unselected population over an 18-year period. BJOG. 2012; 119:113140. | Article | PubMed

8. Romosan G, Henriksson E, Rylander A and Valentin L. Diagnostic performance of routine ultrasound screening for fetal abnormalities in an unselected Swedish population in 2000-2005. Ultrasound Obstet Gynecol. 2009; 34:526-33. | Article | PubMed

9. Garne E, Hansen A. V and Birkelund A. S et al. Major congenital anomalies in a Danish region - prevalence, fetal and infant mortality and chronic maternal diseases. Danish Medical Journal. 2014; 61:A4825. I Article

10. Saari-Kemppainen A, Karjalainen O, Ylostalo P and Heinonen OP. Ultrasound screening and perinatal mortality: controlled trial of systematic one-stage screening in pregnancy. The Helsinki Ultrasound Trial. Lancet. 1990; 336:387-91. | PubMed

11. Santalahti P, Hemminki E, Latikka AM and Ryynanen M. Women's decision-making in prenatal screening. Soc Sci Med. 1998; 46:1067-76. | Article I PubMed

12. McCoyd JL. Preparation for prenatal decision-making: a baseline of knowledge and reflection in women participating in prenatal screening. J Psychosom Obstet Gynaecol. 2013; 34:3-8. | Article | PubMed

13. Viax-savelon S, Dommergues $M$ and Rosenblum $O$ et al. Prenatal ultrasound screening: False positive soft markers may alter maternal representations and mother-infant interactions. PLOS ONE. 2012; 7:e30935. | Article

\section{Citation:}

Honore $\mathrm{KD}$ and Garne E. Trends in prenatal diagnosis of anomalies among live births over a 30-year period. J Reprod Biol Health. 2014; 2:1. http://dx.doi.org/10.7243/2054-0841-2-1 